\title{
Ultra High-performance Liquid Chromatography/Tandem Mass Spectrometry
}

National Cancer Institute

\section{Source}

National Cancer Institute. Ultra High-performance Liquid Chromatography/Tandem

Mass Spectrometry. NCI Thesaurus. Code C122176.

An analytical technique wherein ultra-high performance liquid chromatography is coupled to tandem mass spectrometry in order to separate, identify, and quantify substances in a sample. 